Chin B. Eap · Thierry Buclin · Elisabeth Hustert

Gabriela Bleiber · Kerry Powell Golay

Anne-Catherine Aubert · Pierre Baumann

Amalio Telenti $\cdot$ Reinhold Kerb

\title{
Pharmacokinetics of midazolam in CYP3A4- and CYP3A5-genotyped subjects
}

Received: 1 March 2004/ Accepted: 16 March 2004/Published online: 28 April 2004

(C) Springer-Verlag 2004

\begin{abstract}
Objective: We investigated whether differences in pharmacokinetics of midazolam, a CYP3A probe, could be demonstrated between subjects with different CYP3A4 and CYP3A5 genotypes.

Methods: Plasma concentrations of midazolam, and of total (conjugated + unconjugated) 1'OH-midazolam, and $4^{\prime} \mathrm{OH}$-midazolam were measured after the oral administration of $7.5 \mathrm{mg}$ or of $75 \mu \mathrm{g}$ of midazolam in 21 healthy subjects.

Results: $C Y P 3 A 5^{*} 7, \quad C Y P 3 A 4^{*} 1 E, \quad C Y P 3 A 4^{*} 2$, CYP $3 A 4^{*} 4, \quad C Y P 3 A 4^{*} 5, \quad C Y P 3 A 4^{*} 6, \quad C Y P 3 A 4^{*} 8$, CYP $3 A 4^{*} 11, C Y P 3 A 4^{*} 12, C Y P 3 A 4^{*} 13, C Y P 3 A 4^{*} 17$ and $C Y P 3 A 4^{*} 18$ alleles were not identified in the 21 subjects. $C Y P 3 A 5^{*} 3, C Y P 3 A 5^{*} 6, C Y P 3 A 4^{*} 1 B$ and $C Y P 3 A 4^{*} 1 F$ alleles were identified in $20,1,4$ and 2 subjects, respectively. No statistically significant differences were observed for the $\mathrm{AUC}_{\text {inf }}$ values between the different genotypes after the $75-\mu \mathrm{g}$ or the $7.5-\mathrm{mg}$ dose. Conclusion: Presently, CYP3A4 and CYP3A5 genotyping methods do not sufficiently reflect the inter-individual variability of CYP3A activity.
\end{abstract}

Keywords CYP3A4 CYP3A5 - Phenotyping

C. B. Eap $(\bowtie) \cdot$ K. P. Golay · A.-C. Aubert · P. Baumann

Unit of Biochemistry and Clinical Psychopharmacology,

Centre of Psychiatric Neurosciences,

University Department of Adult Psychiatry,

Hôpital de Cery, 1008 Prilly-Lausanne, Switzerland

E-mail: Chin.Eap@inst.hospvd.ch

Tel.: + 41-21-6436438

Fax: + 41-21-6436444

T. Buclin

Department of Clinical Pharmacology,

University Hospital of Lausanne, Switzerland

E. Hustert · R. Kerb

EPIDAUROS Biotechnologie AG, Am Neuland 1,

Bernried, Germany

G. Bleiber · A. Telenti

Division of Infectious Diseases,

University Hospital of Lausanne, Switzerland

\section{Introduction}

Because of its abundance in the intestine and liver, CYP3A, a term that in adults reflects the collective activity of CYP3A4 and CYP3A5, plays a central role in the metabolism of a wide variety of therapeutic compounds [1]. Considering the large inter-individual and intra-individual variability in CYP3A activity, characterisation of CYP3A activity either by genotyping or phenotyping methods is needed. With regard to genotyping methods, several allelic variants have been characterised for $C Y P 3 A 4$, although these variants predict only to a very limited extent the observed interindividual variability of CYP3A4 activity $[2,3]$. Several variants have also been described for $C Y P 3 A 5$, the most common $C Y P 3 A 5^{*} 3$ allele causing the loss of hepatic CYP3A5, and only people with at least one $C Y P 3 A 5^{*} 1$ allele express large amounts of CYP3A5 $[4,5]$. Because CYP3A5 represents up to $50 \%$ of the total hepatic CYP3A content, it has been suggested that polymorphically expressed CYP3A5 may be an important genetic contributor to inter-individual differences in CYP3Adependent drug clearance [4]. CYP3A5 is the prevailing CYP3A isoform in kidney, and $* 1 / * 3$ individuals had at least an 8-fold higher mean kidney microsomal CYP3A5 content and an 18-fold higher mean CYP3A catalytic activity than $* 3 / * 3$ individuals [6]. Furthermore, the *3 allele was associated with systolic blood pressure, mean arterial pressure, and creatinine clearance among 25 healthy African-American adults [6]. However, there is a large overlap of activity between CYP3A4 and CYP3A5, and a recent study with Chinese people showed that the pharmacokinetics of midazolam (MID), a substrate of both isozymes, is independent of $C Y P 3 A 5$ expression [7]. In another recent study, no significant association was found between homozygosity for the inactivating CYP3A5 mutations and MID or erythromycin metabolic elimination in 57 healthy men and women of either European-American or African-American ancestry [8]. 
MID is a widely accepted probe for phenotyping CYP3A activity [1, 9, 10]. Following oral administration, MID is oxidised to $1^{\prime}-\mathrm{OH}$ midazolam (1OHMID) and $4^{\prime}-\mathrm{OH}$ midazolam (4OHMID) [1]. To validate the use of a very low $(75 \mu \mathrm{g})$ oral dose of MID as a phenotyping probe for CYP3A, we measured the kinetics of oral doses of $75 \mu \mathrm{g}$ MID in 21 healthy subjects free of drugs known as being CYP3 inducers or inhibitors. In addition, the kinetics of an oral dose of $7.5 \mathrm{mg}$ MID was also measured in a subset of 13 subjects [11]. The aim of this study was to test whether different $C Y P 3 A 4$ or $C Y P 3 A 5$ genotypes can explain differences in MID pharmacokinetics in this group of 21 subjects.

\section{Subjects and methods}

\section{Study design}

The protocol of the study on the validation of the very low oral dose of MID for CYP3A phenotyping is described in detail elsewhere [11]. In summary, the study population consisted of 21 healthy volunteers (19 Caucasian, 1 North African, 1 black African, 8 male) who were all free of drugs with the exception of a subject with an oral contraceptive. The study was approved by the ethics committee of the University Department of Psychiatry, and all subjects gave their written informed consent to participate in the study. Subjects had normal hepatic and renal functions, as assessed by standard clinical laboratory tests (ALT, ASP, AP, GGT, urea, creatinine).

The present study was based on pharmacokinetic data obtained in the whole group of 21 subjects following the administration of an oral dose of $75 \mu \mathrm{g}$ MID. The pharmacokinetics of MID was also measured in a subgroup of 13 subjects following the administration of an oral dose of $7.5 \mathrm{mg}$. For the latter subjects, the two sessions, i.e. the session with the $75-\mu \mathrm{g}$ dose and the session with the $7.5-\mathrm{mg}$ dose, were separated by an interval of at least 1 week and at the most 3 weeks.

\section{Blood sampling}

During each session, at approximately 0800 hours, after an overnight fast, an intravenous catheter was inserted into a forearm vein, and a blood sample was taken into a heparinised tube (time 0). The subjects were asked to drink $100 \mathrm{ml}$ water containing either $0.075 \mathrm{mg}$ or $7.5 \mathrm{mg}$ MID, prepared by diluting $75 \mu \mathrm{l}$ of a $1 \mathrm{mg} / \mathrm{ml}$ MID solution into $100 \mathrm{ml}$ water or $1.5 \mathrm{ml}$ of a $5 \mathrm{mg} / \mathrm{ml}$ MID solution into $100 \mathrm{ml}$ water, respectively. The subjects then drank an additional $100 \mathrm{ml}$ water to rinse the glass. After ingestion of $75 \mu \mathrm{g}$ MID, blood samples were taken at $0.5,1,1.5,2,3,4$ and $6 \mathrm{~h}$. After ingestion of $7.5 \mathrm{mg}$ MID, supplemental blood samples were taken at $8 \mathrm{~h}$ and $24 \mathrm{~h}$ (the catheter was removed after the blood sampling at $8 \mathrm{~h}$, the subjects returned home but were asked to come back to the centre for the 24-h blood sample). All blood samplings were performed with subjects in the supine position. The subjects were given a breakfast and a meal, if awake, approximately $1.5 \mathrm{~h}$ and $4.5 \mathrm{~h}$, respectively, after ingestion of the drug. Subjects with the standard dose of MID were asked to lie on a bed until the sedative effects of MID became inconsequential. All subjects were asked to refrain from walking for at least 90 min. After collection, the blood samples were centrifuged within $1 \mathrm{~h}$, and the plasma samples stored at $-20^{\circ} \mathrm{C}$ until analysis.

\section{Determinations of MID and metabolites}

Determination of unconjugated MID, and of total 1OHMID and 4OHMID (unconjugated + conjugated), was performed using gas chromatography-negative chemical ionisation mass spectrometry [12]. Total concentrations were obtained by enzymatic hydrolysis of the glucuronic conjugates. The limits of quantification, as defined by the concentration for which the mean value of replicate determination $(n=8)$ was within $20 \%$ of the actual value, the coefficient of variation less than $20 \%$, and which gave a signal-to-noise ratio of at least 10 , were found to be $10 \mathrm{pg} / \mathrm{ml}$ for the three substances. Intra- and inter-day coefficients of variation determined at three concentrations $(100 \mathrm{pg} / \mathrm{ml}, 500 \mathrm{pg} / \mathrm{ml}, 2 \mathrm{ng} / \mathrm{ml})$ ranged from $1 \%$ to $8 \%$ for MID, from $2 \%$ to $13 \%$ for 1OHMID, and from $1 \%$ to $14 \%$ for 4OHMID [12] The percentage theoretical concentrations, which represent the accuracy of the method, were within $\pm 8 \%$ for MID and 1OHMID, within $\pm 9 \%$ for 4OHMID at $500 \mathrm{pg} / \mathrm{ml}$ and $2 \mathrm{ng} / \mathrm{ml}$, and within $\pm 28 \%$ for 4OHMID at 100 $\mathrm{pg} / \mathrm{ml}$ [12]. 1OHMID to MID ratios were calculated with total concentrations of 1OHMID. These ratios were then multiplied by 325.8 and divided by 341.8 (the former and the latter values being the molecular weights of MID and OHMID, respectively).

\section{Genotyping analyses}

DNA was isolated using standard methods from blood drawn into tubes containing $9 \mathrm{ml}$ potassium-ethylene diamine tetraacetic acid (K-EDTA) and stored at $-20^{\circ} \mathrm{C}$ until use. The $C Y P 3 A 5^{*} 3$ allele was determined by realtime polymerase chain reaction (PCR) with TaqMan (Applied Biosystems, Rotkreuz, Switzerland) according to the manufacturer's instructions. Briefly, the 25- $\mu$ l PCR mixture contained $12.5 \mu \mathrm{l}$ TaqMan Universal PCR master mix $(2 \times$ solution containing AmpliTaq Gold DNA polymerase, AmpErase UNG, dNTPs, and optimised buffer), $700 \mathrm{nM}$ forward primer, $800 \mathrm{nM}$ reverse primer, $2 \mu \mathrm{M}$ each probe and $100 \mathrm{ng}$ DNA. After an activation step of AmpErase $\left(50^{\circ} \mathrm{C}, 2 \mathrm{~min}\right)$ and 
AmpliTaq Gold enzyme activation $\left(95^{\circ} \mathrm{C}, 10 \mathrm{~min}\right), 35$ PCR cycles were performed with $15 \mathrm{~s}$ at $92^{\circ} \mathrm{C}$ and $1 \mathrm{~min}$ at $61^{\circ} \mathrm{C}$. The primers were $5^{\prime}$-CCACCCAGCTTAACGAATGC-3' (forward) and 5'-GAAGGGTAATGTGGTCCAAACAG-3' (reverse), and the probes were 5'-TGTCTTTCAaTATCTCT-3' (FAM) and 5'-TGTCTTTCAgTATCTCT-3' (VIC).

CYP3A5* 6 and 7 alleles were analysed by TaqMan allelic discrimination assays (Applied Biosystems, Germany). PCR was carried out with 50-60 ng DNA, $900 \mathrm{nM}$ each primer, $200 \mathrm{nM}$ each probe, in a total 25- $\mu$ l volume of $1 \times$ TaqMan Universal PCR Master Mix. Cycling conditions were 40 cycles of $15 \mathrm{~s}$ at $92^{\circ} \mathrm{C}$ and $60 \mathrm{~s}$ at $62^{\circ} \mathrm{C}$ after a 10 -min activation step at $95^{\circ} \mathrm{C}$. Amplification was achieved on a GeneAmp PCR System 9700 employing the 9600 emulation modus, and allelespecific detection of the amplicons was performed using the plate reading function of an ABI PRISM 7700. Primer and probe combinations for the specific detection of $C Y P 3 A 5^{*} 6$ and $C Y P 3 A 5^{*} 7$ were $5^{\prime}$-GGC CTA CAG CAT GGA TGT GAT T-3' (forward), 5'-AAA TAA TAG CCC ACA TAC TTA TTG AGA GAA AT-3' (reverse), 5'-VIC-AGC ACT AAg AAG TTC CTA AA$3^{\prime}$ and 5'-FAM-AGA GCA CTA AaA AGT TCC TAA3'; and 5'- CTC AGA TTA TCC AAT TCT GTT TCT TTC $\mathrm{C}-3^{\prime}$ (forward), 5'-ATT GAT TTC AAC ATC TTT CTT GCA AGT-3' (reverse), 5'-VIC-CAC CAC CTa CCT ATG AT-3' and 5'-FAM-CAC CAC CTt ACC TAT GAT- $3^{\prime}$, respectively.

CYP $3 A 4 * 1 B, * 1 E, * 1 F, * 2, * 4, * 5, * 6, * 8, * 11, * 12$, $* 13, * 17$ and *18 alleles were detected by Dye Terminator sequencing of gene-specific PCR fragments. PCRs were carried out in 50- $\mu$ l reaction volumes employing 20-40 ng DNA template, 1 U Taq polymerase (Qiagen, Germany), $200 \mu \mathrm{M}$ dNTP mix (Roth, Karlsruhe, Germany), 1× Taq buffer (Qiagen, Hilden, Germany) and $250 \mathrm{nM}$ of primers 5'-AGA GCC ATG ACA GGG AAT AAG ACT AGA-3' (forward) and 5'-TGG GCT ATG TGC ATG GAG CTT-3' (reverse) for CYP3A4*1B and *1E, 5'-CCA CTC TTT GGC AAA GAA CCT GTC T-3' (forward) and 5'-CCC TTC ATG CAA TCC TAT TGT CCT-3' (reverse) for CYP3A4*1F, 5'-CTA CAA CCA TGG AGA CCT CC-3' (forward) and 5'-TAC CTG TCC CCA CCA GAT TC-3' (reverse) for CYP3A4*4 and *8, 5'-TGA CTG GAC ATG TGG GTT TCC TGT-3' (forward) and 5'-GCT GAT AGC TAA AAA TGT ATG AGG TCT C-3' (reverse) for CYP3A4*2, *5, *16, *17, 5'-GAG CCT TCC CGA ATG CTT CCC A-3' (forward) and 5'-GGA CAT AAC TGA TGA CCT TCA TCG-3' (reverse) for CYP3A4*11, -*12, and -*13, 5'-GGA GAT CAA GGA CCA CGC TTG TG-3' (forward) and $5^{\prime}$-CTC ATC ATC CTG GAA TAC TTC CTG C-3' (reverse) for CYP3A4*6, and 5'-CCC AGT GTA CCT CTG AAT TGC-3' (forward) and 5'-CAG AGC CTT CCT ACA TAG-3' (reverse) for CYP3A4*18. A GeneAmp PCR System 9700 (Applied Biosystems, Germany) was used for 34 cycles of $94^{\circ} \mathrm{C}(45 \mathrm{~s}), 62^{\circ} \mathrm{C}(45 \mathrm{~s})$ and $72^{\circ} \mathrm{C}(60 \mathrm{~s})$ after an initial denaturation step of $120 \mathrm{~s}$ at $94^{\circ} \mathrm{C}$.
PCR products were cleaned using the QIAquick purification system on a Qiagen BioRobot 9600 (Qiagen, Hilden, Germany) and 30-80 ng were sequenced in the forward direction using $5 \mathrm{pmol}$ of the respective PCR primers and the Big Dye Terminator cycle sequencing kit (Applied Biosystems, Weiterstadt, Germany) in 10 - to $20-\mu 1$ volumes supplemented by $5 \%$ DMSO $(\mathrm{v} / \mathrm{v})$. Cycling conditions were as follows: initial denaturation at $96^{\circ} \mathrm{C}$ for $10 \mathrm{~s}$, followed by 25 cycles of $96^{\circ} \mathrm{C}$ for $10 \mathrm{~s}$ and $60^{\circ} \mathrm{C}$ for $4 \mathrm{~min}$ on a GeneAmp PCR System 9700 (Applied Biosystems, Weiterstadt, Germany). The DNA sequences of the standard isopropanol-precipitated PCR fragments were obtained on an automated ABI3700 capillary sequencer (Applied Biosystems, Weiterstadt, Germany), assembled and SNPs identified using the phredPhrap, Consed, and PolyPhred software package (University of Washington, Seattle, USA).

\section{Data analysis}

The concentrations of MID, and of total 1OHMID and 4OHMID determined after each administration were plotted against time according to the dosage level. The individual curves were then characterised by their area under the curve calculated by log-trapezoidal rule with extrapolation to infinity $\left(\mathrm{AUC}_{\mathrm{inf}}\right)$. All calculations were performed using the non-compartmental method implemented in the program Kinetica (version 4.0, Innaphase, Buckinghamshire, UK). Comparisons between different groups of subjects were performed using Kruskall-Wallis test (Statistix version 7; Analytical Software, Tallahassee, FL). Power analysis was performed using the two-sample $t$-test power analysis (NCSS Trial and PASS 2000, NCSS, Kaysville, Utah, USA). The differences were appreciated considering a significance level of $P<0.05$.

\section{Results}

Genotype analyses identified 20 carriers of the $C Y P 3 A 5^{*} 3$ allele among the 21 study subjects (one homozygous wild-type $C Y P 3 A 5^{*} 1 / * 1$, three heterozygous $C Y P 3 A 5^{*} 1 / * 3,17$ homozygous $\left.C Y P 3 A 5^{*} 3 / * 3\right)$. $C Y P 3 A 5^{*} 7$ was not detected while $C Y P 3 A 5^{*} 6$ was detected in only one subject of Black-African origin, who was shown to be heterozygous $C Y P A 5^{*} 11^{*} 6$. As the $C Y P 3 A 5^{*} 6$ allele generates an mRNA lacking exon 7 [4], 17 subjects could be classified as CYP3A5 poor metabolisers $\left(C Y P 3 A 5^{*} 3 / * 3\right)$ and 4 subjects as heterozygous extensive metabolisers (one $C Y P 3 A 5^{*} 11^{*} 6$ and three $\left.C Y P 3 A 5^{*} 11^{*} 3\right)$. $C Y P 3 A 4^{*} 1 E, C Y P 3 A 4^{*} 2, C Y P 3$ $A 4^{*} 4, \quad C Y P 3 A 4^{*} 5, \quad C Y P 3 A 4^{*} 6, \quad C Y P 3 A 4^{*} 8, C Y P 3$ $A 4^{*} 11, C Y P 3 A 4^{*} 12, C Y P 3 A 4^{*} 13, C Y P 3 A 4^{*} 17$ and $C Y P 3 A 4 * 18$ were not identified. Among the 21 subjects, genotype analyses identified 4 carriers of the $C Y P 3 A 4 * 1 B$ allele (one homozygous $C Y P 3 A 4 * 1 B /{ }^{*} 1 B$ who was the subject of Black-African origin, three 
heterozygous $C Y P 3 A 4^{*} 11^{*} 1 B$ ), and 2 carriers of the $C Y P 3 A 4^{*} 1 F$ (2 heterozygous $\left.C Y P 3 A 4^{*} 1 / * 1 F\right)$.

$\mathrm{AUC}_{\text {inf }}$ values of MID measured after the $7.5-\mathrm{mg}$ dose in 13 subjects were (mean $\pm \mathrm{SD}$, median, range): $67 \pm 30 \mathrm{~h} \mathrm{ng} / \mathrm{ml}, 61 \mathrm{~h} \mathrm{ng} / \mathrm{ml}, 35-135 \mathrm{~h} \mathrm{ng} / \mathrm{ml}$. After the $75-\mu \mathrm{g}$ dose in 21 subjects they were: $0.68 \pm 0.25 \mathrm{~h} \mathrm{ng} / \mathrm{ml}$, $0.71 \mathrm{~h} \mathrm{ng} / \mathrm{ml}, 0.23-1.17 \mathrm{~h} \mathrm{ng} / \mathrm{ml}$ [11]. When comparing the group of nine CYP3A5 poor metabolisers with the four extensive metabolisers who received the $7.5-\mathrm{mg}$ dose of MID, the mean $\mathrm{AUC}_{\text {inf }}$ value of MID was lower in the CYP3A5 extensive (mean $\pm \mathrm{SD}$, median, range: $55 \pm 10 \mathrm{~h} \mathrm{ng} / \mathrm{ml}, 58 \mathrm{~h} \mathrm{ng} / \mathrm{ml}, 40-63 \mathrm{~h} \mathrm{ng} / \mathrm{ml}$ ) than in the poor $(72 \pm 34 \mathrm{~h} \mathrm{ng} / \mathrm{ml}, 61 \mathrm{~h} \mathrm{ng} / \mathrm{ml}, 35-135 \mathrm{~h} \mathrm{ng} / \mathrm{ml})$ metabolisers, although this difference was not statistically significant $(P=0.34$; Fig. 1$)$. However, the total 1OHMID $\mathrm{AUC}_{\mathrm{inf}} /$ total 4OHMID $\mathrm{AUC}_{\text {inf }}$ ratio was significantly higher in the CYP3A5 extensive than in the poor metaboliser group $(19 \pm 5,19,13-26$ versus $12 \pm 3$, 11, 7-18; $P<0.02$; Fig. 1). Neither the subject of North African origin $\left(C Y P 3 A 5^{*} 3 / * 3\right.$; data not shown) nor the subject of Black-African origin $\left(C Y P 3 A 5^{*} 1\right)^{*} 6$; Fig. 1) were outliers when considering their $\mathrm{AUC}_{\text {inf }}$ value or their total 1OHMID $\mathrm{AUC}_{\mathrm{inf}} /$ total 4OHMID $\mathrm{AUC}_{\mathrm{inf}}$ ratio. Mean $\mathrm{AUC}_{\mathrm{inf}}$ values were not significantly different between subjects without $(73 \pm 34 \mathrm{~h} \mathrm{ng} / \mathrm{ml}, 61 \mathrm{~h}$ $\mathrm{ng} / \mathrm{ml}, 40-135 \mathrm{~h} \mathrm{ng} / \mathrm{ml}$ ) or with the $C Y P 3 A 4^{*} 1 B$ allele $(53 \pm 13 \mathrm{~h} \mathrm{ng} / \mathrm{ml}, 58 \mathrm{~h} \mathrm{ng} / \mathrm{ml}, 35-63 \mathrm{~h} \mathrm{ng} / \mathrm{ml})$. The two carriers of the $C Y P 3 A 4^{*} 1 F$ allele did not appear to be outliers with regard to their $\mathrm{AUC}_{\text {inf }}$ values when compared with non-carriers of this allele (data not shown). Finally, a comparison of the $\mathrm{AUC}_{\text {inf }}$ values or the 30-min MID with total 1OHMID ratio, determined after the administration of the 75- $\mu$ g MID dose in the 21 subjects did not show any statistically significant differences between the different $C Y P 3 A 4$ and $C Y P 3 A 5$ genotypes (data not shown).

\section{Discussion}

In a previous study, the pharmacokinetics of an oral dose of $75 \mu \mathrm{g}$ and $7.5 \mathrm{mg}$ MID was measured in a group of 21, and in a subgroup of 13 healthy subjects, respectively [11]. During that study, we validated the use of the 75- $\mu \mathrm{g}$ oral dose of MID as a phenotyping probe for CYP3A and showed that the 30-min total 1OHMID to MID ratio can be reliably used as an indicator of MID clearance [11]. The aim of the present study was to genotype the 21 subjects for different CYP3A4 and CYP3A5 alleles, and to determine whether differences in MID pharmacokinetics could be demonstrated between genotypes. With regard to $C Y P 3 A 4$, the absence of CYP $3 A 4^{*} 1 E, \quad C Y P 3 A 4^{*} 2, \quad C Y P 3 A 4 * 4, \quad C Y P 3 A 4^{*} 5$, $C Y P 3 A 4^{*} 6, C Y P 3 A 4 * 8, C Y P 3 A 4^{*} 11, C Y P 3 A 4 * 12$, $C Y P 3 A 4^{*} 13, C Y P 3 A 4^{*} 17$ and $C Y P 3 A 4^{*} 18$ alleles in this group of 21 subjects is expected as these SNPs have been detected at low frequencies in Caucasian and/or other populations $[2,3,13,14,15]$. No change in MID $\mathrm{AUC}_{\mathrm{inf}}$ was observed for the four carriers of the $C Y P 3 A 4^{*} 1 B$ allele which corresponds to a polymorphism in the $5^{\prime}$-promoter (nifedipine-specific element) region $[16,17,18]$. The frequency of this allele was found to be $4 \%$ and $67 \%$ in Caucasians and black subjects, respectively [2]. A small difference $(19 \%$ decrease) of systemic clearance of MID was observed in 10 African-American $\mathrm{G} / \mathrm{G}$ homozygotes when compared with 15 European-American A/A homozygotes $(252 \pm 53$ versus $310 \pm 54 \mathrm{ml} / \mathrm{min}, P=0.02)$ [18]. The inclusion of only one homozygous and three heterozygous in the present study is therefore too low to detect such a small difference in MID kinetics. With regard to $C Y P 3 A 4^{*} 1 F$, the inclusion of only two heterozygous carriers does not allow to draw a conclusion on the
Fig. 1 Midazolam AUC $\mathrm{C}_{\text {inf }}$ values (filled triangle) and total 1-OH-midazolam $\mathrm{AUC}_{\text {inf }}$ / 4-OH-midazolam $\mathrm{AUC}_{\text {inf }}$ ratios (filled square) measured in four CYP3A5 extensive metabolisers $\left(C Y P 3 A 5^{*} 11^{*} 6\right.$ and $\left.C Y P 3 A 5^{*} 1 / * 3\right)$ and nine CYP3A5 poor metabolisers $\left(C Y P 3 A 5^{*} 3 / * 3\right)$ after the oral administration of $7.5 \mathrm{mg}$ midazolam. The mean value is indicated in each group by a bar. The subject of BlackAfrican origin $\left(C Y P 3 A 5^{*} 1 / * 6\right.$ and $\left.C Y P 3 A 4^{*} 1 B / * 1 B\right)$ is indicated by empty figures

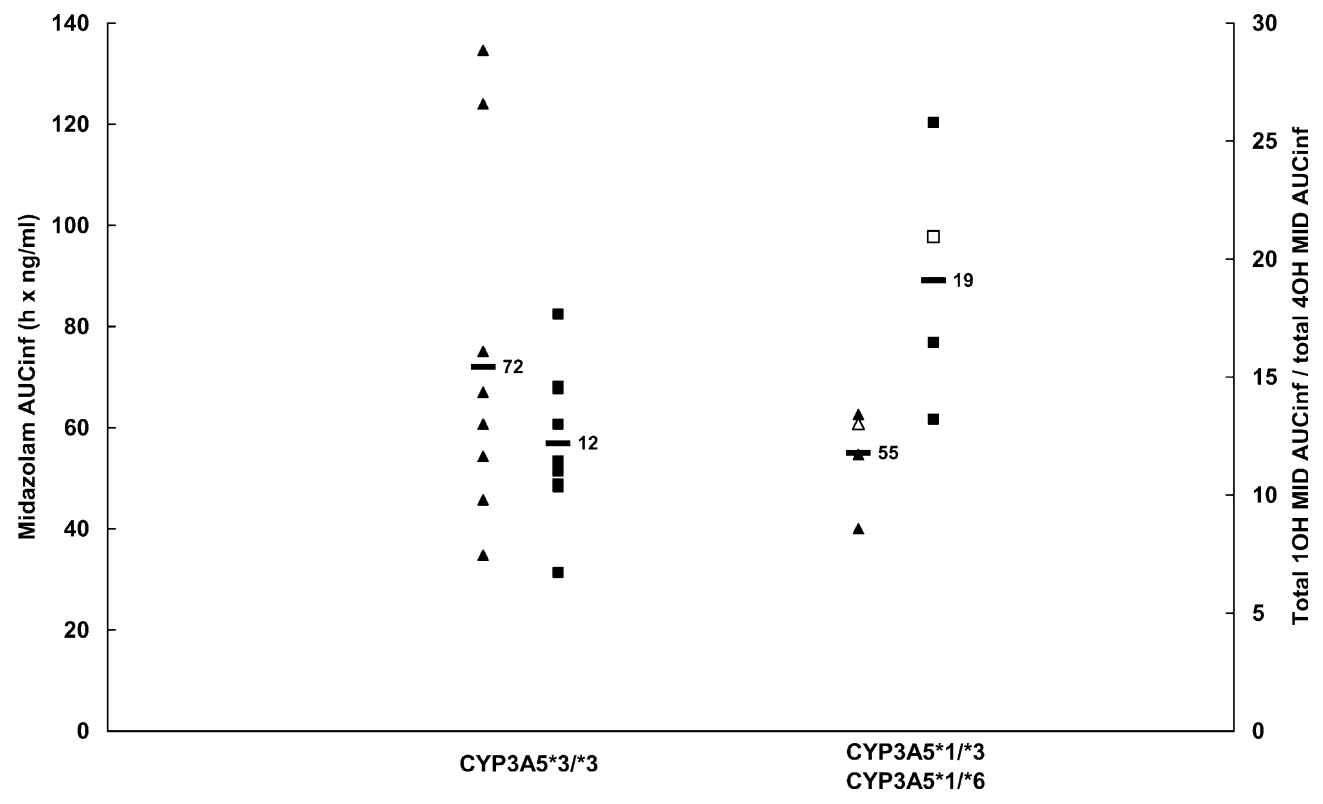


absence of influence of this allele on MID AUC $\mathrm{Anf}_{\text {, as }}$ noted in the present study, but no particular phenotype has previously been associated with this allele [15].

With regard to $C Y P 3 A 5$, the presence of the $C Y P 3 A 5^{*} 6$ allele in the lone subject of Black-African origin is in accordance with the predominance of this SNP in this ethnic group compared with Caucasians [4, 5]. Although a lower mean $\mathrm{AUC}_{\text {inf }}$ value was measured in the CYP3A5 extensive metabolisers relative to the poor metabolisers after the 7.5-mg dose, this difference was not statistically significant. This lack of influence of the CYP3A5 genotype on MID pharmacokinetics could first be due to the absence of homozygous extensive metabolisers $\left(C Y P 3 A 5^{*} 1 /^{*} 1\right)$. It must be mentioned that this low frequency of homozygous extensive metabolisers is in agreement with other studies in Caucasians [4, 5]. Second, the number of subjects included in the present study could be too low and lack the statistical power to detect a significant difference. Thus, a power analysis indicated that with a mean $\pm \mathrm{SD}$ value of $72 \pm 34 \mathrm{~h} \mathrm{ng} / \mathrm{ml}$ for the $\mathrm{AUC}_{\mathrm{inf}}$ in the extensive metaboliser after the 7.5-mg dose (see Results), the inclusion of four extensive and nine poor metabolisers allows the achievement of an $80 \%$ power to detect a twofold difference in the mean $\mathrm{AUC}_{\text {inf }}$ between the two groups with a significance level (alpha) of 0.05 (onesided $t$-test). As a less than twofold difference was measured between the two groups in the present study, the inclusion of a higher number of subjects (i.e. for example 27 in each group) would have been necessary. However, the results of the present study are in agreement with those of a recent study in Chinese, which found no significant differences in the pharmacokinetics of MID, and 1OHMID between CYP3A5 poor metabolisers $\left(C Y P 3 A 5^{*} 3 / * 3, \mathrm{n}=14\right)$ and heterozygous extensive metabolisers $\left(C Y P 3 A 5^{*} 1 / * 3, \mathrm{n}=12\right)$ [7]. In another recent study with 57 healthy men and women of either European-American or African-American ancestry genotyped for $C Y P 3 A 4^{*} 1 B, C Y P 3 A 5^{*} 3, C Y P 3 A 5^{*} 6$ and $C Y P 3 A 5^{*} 7$, no association was noted between any genotypes and MID or erythromycin metabolic elimination [8]. However, it has been suggested that the presence of the $C Y P 3 A 4^{*} 1 B$ allele and the inversely linked $C Y P 3 A 5^{*} 3$ polymorphism might influence the induction of oral clearance of MID by rifampicin [8]. In the present study, four subjects were also treated with rifampicin during a separate session [11]. However, as all four subjects were CYP3A5 poor metabolisers $\left(C Y P 3 A 5^{*} 3 / * 3\right)$, no data supporting a genetic influence on the induction of CYP3A activity could be demonstrated.

Finally, and interestingly, the significantly higher total 1OHMID $\mathrm{AUC}_{\text {inf }} /$ total 4OHMID $\mathrm{AUC}_{\text {inf }}$ ratios measured in the present study in the extensive relative to the poor metabolisers are in agreement with in vitro data showing that microsomal samples containing CYP3A5 and CYP3A4 exhibited a greater ratio of 1OHMID to 4OHMID compared with samples containing CYP3A4 alone $[4,19]$. This result is explained by the regioselectivity of CYP3A5 in favour of 1OHMID relative to
4OHMID, a selectivity that depends on MID concentration $[19,20]$. In the present study, with the $7.5-\mathrm{mg}$ dose (pharmacokinetic parameters of 4OHMID were not assessable with the 75- $\mu$ g dose; [11]), although the mean total 1OHMID/total 4OHMID $\mathrm{AUC}_{\text {inf }}$ ratios were significantly different between both groups, the largely overlapping ranges prevented the use of this ratio as a discriminating factor between subjects without and with CYP3A5 activity.

In summary, in this group of 21 healthy subjects, the presently known CYP3A4 and CYP3A5 genotypes do not sufficiently reflect the inter-individual variability in the activity of these two isozymes.

Acknowledgements The authors thank Mrs V. Sari and Mrs C. Bertschi for editorial assistance, Mrs E. Ponce, Mrs J. Rosselet and Mrs M. Gobin for bibliographic help. This work was supported in part by the Swiss National Research Foundation (project 3200-065427.01).

\section{References}

1. Wrighton SA, Thummel KE (2000) CYP3A. In: Metabolic drug interactions. Levy RH, Thummel KE, Trager WF, Hansten PD, Eichelbaum M (eds) Lippincott Williams and Wilkins, Philadelphia, pp 115-133

2. Sata F, Sapone A, Elizondo G, Stocker P, Miller VP, Zheng W, Raunio H, Crespi CL, Gonzalez FJ (2000) CYP3A4 allelic variants with amino acid substitutions in exons 7 and 12: evidence for an allelic variant with altered catalytic activity. Clin Pharmacol Ther 67:48-56

3. Eiselt R, Domanski TL, Zibat A, Mueller R, Presecan-Siedel E, Hustert E, Zanger UM, Brockmöller J, Klenk HP, Meyer UA, Khan KK, He YA, Halpert JR, Wojnowski L (2001) Identification and functional characterization of eight CYP3A4 protein variants. Pharmacogenetics 11:447-458

4. Kuehl P, Zhang J, Lin Y, Lamba J, Assem M, Schuetz J, Watkins PB, Daly A, Wrighton SA, Hall SD, Maurel P, Relling M, Brimer C, Yasuda K, Venkataramanan R, Strom S, Thummel K, Boguski MS, Schuetz E (2001) Sequence diversity in CYP3A promoters and characterization of the genetic basis of polymorphic CYP3A5 expression. Nat Genet 27:383-391

5. Hustert E, Haberl M, Burk O, Wolbold R, He YQ, Klein K, Nuessler AC, Neuhaus P, Klattig J, Eiselt R, Koch I, Zibat A, Brockmöller J, Halpert JR, Zanger UM, Wojnowski L (2001) The genetic determinants of the CYP3A5 polymorphism. Pharmacogenetics 11:773-779

6. Givens RC, Lin YS, Dowling ALS, Thummel KE, Lamba JK, Schuetz EG, Stewart PW (2003) CYP3A5 genotype predicts renal CYP3A activity and blood pressure in healthy adults. J Appl Physiol 95:1297-1300

7. Shih PS, Huang JD (2002) Pharmacokinetics of midazolam and 1'-hydroxymidazolam in Chinese with different CYP3A5 genotypes. Drug Metab Dispos 30:1491-1496

8. Floyd MD, Gervasini G, Masica AL, Mayo G, George AL Jr, Bhat K, Kim RB, Wilkinson GR (2003) Genotype-phenotype associations for common CYP3A4 and CYP3A5 variants in the basal and induced metabolism of midazolam in European- and African-American men and women. Pharmacogenetics 13:595606

9. Watkins PB (1994) Noninvasive tests of CYP3A enzymes. Pharmacogenetics 4:171-184

10. Streetman DS, Bertino JS Jr, Nafziger AN (2000) Phenotyping of drug-metabolizing enzymes in adults: a review of in-vivo cytochrome $\mathrm{P} 450$ phenotyping probes. Pharmacogenetics 10:187-216 
11. Eap CB, Buclin T, Cuccia G, Zullino D, Hustert E, Bleiber G, Powell Golay K, Aubert A-C, Baumann P, Telenti A, Kerb R (2004) Oral administration of a low dose of midazolam $(75 \mu \mathrm{g})$ as an in vivo probe for CYP3A activity. Eur J Clin Pharmacol (in press)

12. Eap CB, Bouchoux G, Powell Golay K, Baumann P (2004) Determination of picogram levels of midazolam, and 1-and 4-hydroxymidazolam in human plasma by gas chromatography-negative chemical ionization-mass spectrometry. J Chromatogr B 802:339-345

13. Hsieh KP, Lin YY, Cheng CL, Lai ML, Lin MS, Siest JP, Huang JD (2001) Novel mutations of CYP3A4 in Chinese. Drug Metab Dispos 29:268-273

14. Dai D, Tang J, Rose R, Hodgson E, Bienstock RJ, Mohrenweiser HW, Goldstein JA (2001) Identification of variants of CYP3A4 and characterization of their abilities to metabolize testosterone and chlorpyrifos. J Pharmacol Exp Ther 299:825831

15. Hamzeiy H, Vahdati-Mashhadian N, Edwards HJ, Goldfarb PS (2002) Mutation analysis of the human CYP3A4 gene 5' regulatory region: population screening using non-radioactive SSCP. Mutat Res 500:103-110
16. Rebbeck TR, Jaffe JM, Walker AH, Wein AJ, Malkowicz SB (1998) Modification of clinical presentation of prostate tumors by a novel genetic variant in CYP3A4. J Natl Cancer Inst 90:1225-1229

17. Westlind A, Lofberg L, Tindberg N, Andersson TB, IngelmanSundberg M (1999) Interindividual differences in hepatic expression of CYP3A4: relationship to genetic polymorphism in the $5^{\prime}$-upstream regulatory region. Biochem Biophys Res Commun 259:201-205

18. Wandel C, Witte JS, Hall JM, Stein CM, Wood AJJ, Wilkinson GR (2000) CYP3A activity in African-American and EuropeanAmerican men: population differences and functional effect of the CYP3A4*1B 5'-promoter region polymorphism. Clin Pharmacol Ther 68:82-91

19. Gorski JC, Hall SD, Jones DR, VandenBranden M, Wrighton SA (1994) Regioselective biotransformation of midazolam by members of the human cytochrome P450 3A (CYP3A) subfamily. Biochem Pharmacol 47:1643-1654

20. Williams JA, Ring BJ, Cantrell VE, Jones DR, Eckstein J, Ruterbories K, Hamman MA, Hall SD, Wrighton SA (2002) Comparative metabolic capabilities of CYP3A4, CYP3A5, and CYP3A7. Drug Metab Dispos 30:883-891 